\title{
Geometric relaxation time of induced polarization fractal dimension for characterizing Shajara Reservoirs of the Shajara formation of the Permo- Carboniferous Unayzah Group-Permo
}

\author{
Alkhidir KEME* \\ Department of Petroleum and Natural Gas Engineering, College of Engineering, King Saud University, Saudi Arabia
}

\section{Article Info}

*Corresponding author:
Khalid Elyas Mohamed Elameen Alkhidir, PhD
Department of Petroleum and Natural Gas
Engineering
College of Engineering
King Saud University
Saudi Arabia
E-mail: kalkhidir@ksu.edu.sa

Received: November 6, 2017

Accepted: January 27, 2018

Published: February 2, 2018

\begin{abstract}
Citation: AlKhidir KEME. Geometric relaxation time of induced polarization fractal dimension for Characterizing Shajara Reservoirs of the Shajara Formation of the Permo-Carboniferous Unayzah Group-permo. Int I Petrochem Res. 2018; 2(1): 105-108.

doi: 10.18689/jpr-1000119
\end{abstract}

\section{Copyright: @ 2018 The Author(s). This work is licensed under a Creative Commons Attribution 4.0 International License, which permits unrestricted use, distribution, and reproduction in any medium, provided the original work is properly cited.}

Published by Madridge Publishers

\begin{abstract}
Sandstone samples were collected from the surface type section of the Shajara Formation of the Permo-Carboniferous Unayzah Group for detailed reservoir characterization. Capillary pressure experiment was performed to contact porosity and permeability was derived from the Data. Geometric relaxation time of induced polarization was calculated from the distribution of pores and the fractal dimension was proven from the relationship between water saturation and geometric relaxation time of induced polarization. In addition to field observation and obtained results of fractal dimension, the Shajara reservoirs of the Shajara Formation of the permo-Carboniferous Unayzah Group were divided here into three fractal dimension units. The Units from base to top are: Lower Shajara Geometric Relaxation Time Fractal dimension Unit, Middle Shajara Geometric Relaxation Time Fractal Dimension Unit, and Upper Shajara Geometric Relaxation Time Fractal Dimension Unit. These units were also proved by arithmetic relaxation time of induced polarization fractal dimension. It was found that the geometric relaxation time fractal dimension is similar to the arithmetic relaxation time fractal dimension of induced polarization. It was also reported that the obtained fractal dimension speeds with increasing permeability and relaxation time due to an increase in pore connectivity.
\end{abstract}

Keywords: Shajara Formation; Unayzah group; geometric relaxation time fractal dimension; arithmetic relaxation time fractal dimension

\section{Introduction}

The phenomenon of electrical induced polarization (IP) in water-bearing sediments was reported by [1]. Laboratory study of induced polarization in sandstone rocks with varying salinity and shalyness was investigated by [2]. An increase of induced polarization effect with increasing permeability, increasing porosity, and decreasing shalyness was examined by [2]. An increase of permeability with increasing geometric and arithmetic induced polarization relaxation time and increasing porosity was confirmed by [3].

A new integrated model with relaxation time spectra, porosity and formation factor was proposed to predict permeability was recognized by [4]. Bimodal Pore Size behavior of the Shajara Formation reservoirs of the permo-carboniferous Unayzah group was investigated by [5]. Subdivision of the Shajara reservoirs into three units based on thermodynamic fractal dimension approach and 3-D fractal geometry model of mercury intrusion technique was reported by [6]. New Finding reported from King Saud University 
Describe advances in Geoscience was reported by [7]. Subdivision of the Shajara reservoirs into three units: Lower Shajara Differential Capacity Fractal Dimension Unit, Middle Shajara Differential Capacity Fractal Dimension Unit, Upper Shajara Differential Capacity Fractal Dimension Unit was described by [8]. Pressure head fractal dimension for characterizing Shajara Reservoirs of the Shajara Formation of the Permo-Carboniferous Unayzah Group, Saudi Arabia was studied by [9].

\section{Method}

The geometric relaxation time of induced polarization can be scaled as

$S W=\left[\frac{\operatorname{IPTg}^{1.57^{\frac{1}{2}}}}{\text { IPTgmax }^{1.57^{\frac{1}{2}}}}\right]^{3-\mathrm{DI}}$

Where Sw the water saturation, IPTg the geometric relaxation time of induced polarization, IPT gmax the maximum geometric relaxation time of induced polarization, and Df the fractal dimension.

Equation 1 can be proofed from

$\mathrm{k}=9.6 *\left(\operatorname{IPTg} * \Phi^{4}\right)^{1.57}$

Where $\mathrm{k}$ the permeability in millidarcy, 9.6 constant, IPTg geometric relaxation time of induced polarization in milliseconds; $\Phi$ the porosity; and 1.57 constant.

The maximum permeability can be scaled as

$\operatorname{kmax}=9.6 *\left(\text { IPTgmax } * \Phi^{4}\right)^{1.57} \quad 3$

Divide equation 2 by equation 3

$\left[\frac{\mathrm{k}}{\mathrm{kmax}}\right]=\frac{\left[9.6 *\left[\mathrm{IPTg} * \Phi^{4}\right]^{1.57}\right]}{\left[9.6 *\left[\mathrm{IPTgmax} * \Phi^{4}\right]^{1.57}\right]} \quad 4$

Equation 4 after simplification will become

$\left[\frac{\mathrm{k}}{\mathrm{kmax}}\right]=\frac{[\mathrm{IPTg}]^{1.57}}{\left[\text { IPTgmax }^{1.57}\right.}$

Take the square root of equation 5

$\sqrt{\left[\frac{\mathrm{k}}{\mathrm{kmax}}\right]}=\sqrt{\frac{{\left[\text { IPTg }^{1.57}\right.}^{[\text {IPTgmax }]^{1.57}}}{}}$

Equation 6 can also be written as

$\left[\frac{k^{\frac{1}{2}}}{\operatorname{kmax}^{\frac{1}{2}}}\right]=\left[\frac{\operatorname{IPTg}^{1.57^{\frac{1}{2}}}}{\text { IPTgmax }^{1.57^{\frac{1}{2}}}}\right]$

Take the Logarithm of equation 7

$\log \left[\frac{k^{\frac{1}{2}}}{\operatorname{kmax}^{\frac{1}{2}}}\right]=\log \left[\frac{\operatorname{IPTg}^{1.57^{1}}}{\text { IPTgmax }^{1.57^{\frac{1}{2}}}}\right]$

But; $\log \left[\frac{\mathbf{k}^{\frac{1}{2}}}{\text { kmax }^{\frac{1}{2}}}\right]=\log \frac{\text { Sw }}{3-\text { Df }}$

Insert equation 9 into equation 8

$\log \frac{\text { Sw }}{3-\text { Df }}=\log \left[\frac{\text { IPTg }^{1.57^{\frac{1}{2}}}}{\text { IPTgmax }^{1.57^{\frac{1}{2}}}}\right]$

If we remove the Log from equation 10

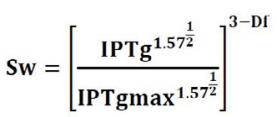

Equation 11 the proof of equation 1 which relates the water saturation, the geometric relaxation time of induced polarization, the maximum geometric relaxation time of induced polarization, and the fractal dimension

The arithmetic relaxation time of induced polarization can be scaled as

$\mathrm{SW}=\left[\frac{\operatorname{IPTa}^{(1.74)^{\frac{1}{2}}}}{\operatorname{IPTamax}^{(1.74)^{\frac{1}{2}}}}\right]^{3-\mathrm{Df}}$

Where Sw the water saturation, IPTa the induced polarization relaxation time arithmetic, IPTa max the maximum induced polarization relaxation time arithmetic, and Df the fractal dimension.

Equation 12 can be proofed from

$\mathrm{k}=11.1\left(\mathrm{IPTa} * \Phi^{4}\right)^{1.74}$

13

Where $k$ the permeability in milldary, 11.1 constant, IPTa the induced polarization relaxation time in milliseconds, $\Phi$ the porosity, and 1.74 constant.

The maximum permeability can be scaled as

$\operatorname{kmax}=11.1\left(\text { IPTamax } * \Phi^{4}\right)^{1.74} \quad 14$

Divide equation 13 by equation 14

$\left[\frac{\mathrm{k}}{\mathrm{kmax}}\right]=\left[\frac{11.1\left(\mathrm{IPTa} * \Phi^{4}\right)^{1.74}}{11.1\left(\mathrm{IPT} \operatorname{amax} * \Phi^{4}\right)^{1.74}}\right]$

15

Equation 15 after simplification will become

$\left[\frac{\mathrm{k}}{\mathrm{kmax}}\right]=\left[\frac{\text { IPTa }^{1.74}}{\text { IPTamax }^{1.74}}\right]$

16

Take the square root of equation 16

$\sqrt{\left[\frac{\mathrm{k}}{\mathrm{kmax}}\right]}=\sqrt{\left[\frac{\mathrm{IPT}^{1.74}}{\mathrm{IPTmax}^{1.74}}\right]}$

Equation 17 can also be written as

$\left[\frac{\mathrm{k}^{\frac{1}{2}}}{\operatorname{kmax}^{\frac{1}{2}}}\right]=\left[\frac{\operatorname{IPTa}^{(1.74)^{\frac{1}{2}}}}{\operatorname{IPTamax}} \cos ^{(1.7)^{\frac{1}{2}}}\right]$

Take the logarithm of equation 18

$\log \left[\frac{k^{\frac{1}{2}}}{\operatorname{kmax}^{\frac{1}{2}}}\right]=\log \left[\frac{\operatorname{IPTa}^{(1.74)^{\frac{1}{2}}}}{\operatorname{IPTamax}^{(1.74)^{\frac{1}{2}}}}\right] \quad 19$

But; $\log \left[\frac{\mathrm{k}^{\frac{1}{2}}}{\mathrm{kmax}^{\frac{1}{2}}}\right]=\frac{\operatorname{LogSw}}{3-\mathrm{Df}}$

Insert equation 20 into equation 19

$\frac{\operatorname{LogSW}}{3-\mathrm{Df}}=\log \left[\frac{\operatorname{IPT}^{(1.74)^{\frac{1}{2}}}}{\operatorname{IPTamax}^{(1.74)^{\frac{1}{2}}}}\right] \quad 21$

If we remove the Log from equation 21

$\mathrm{SW}=\left[\frac{\operatorname{IPTa}^{(1.74)^{\frac{1}{2}}}}{\operatorname{IPTamax}^{(1.74)^{\frac{1}{2}}}}\right]^{3-\mathrm{Df}} \quad 22$

Equation 22 the proof of equation 12 which relates the water saturation Sw. the arithmetic relaxation time of induced polarization IPTa, the maximum arithmetic relaxation time of induced polarization IPTa max, and the fractal dimension Df. 
Porosity was measured on collected sandstone samples from the surface type section of the Shajara formation of the permo-carboniferous Unayzah Group. Permeability was objective of this paper is to calculate the geometric relaxation time and arithmetic relaxation time of induced polarization from the distribution of pores and to calculate the fractal dimension from the relaxation time.

\section{Results and Discussion}

Based on field observation the Shajara Reservoirs of the Shajara Formation of the Permo-Carboniferous Unayzah Group were divided into three units as described in figure1. These units from base to top are: Lower Shajara Reservoir, Middle Shajara reservoir, and Upper Shajara Reservoir.

Their acquired results of the geometric relaxation time fractal dimension and arithmetic relaxation time fractal dimension of induced polarization are displayed in table 1. Based on the attained results it was found that the geometric relaxation time fractal dimension is equal to the arithmetic relaxation time fractal dimension. The maximum value of the fractal dimension was found to be 2.7872 assigned to sample SJ13 from the Upper Shajara Reservoir as verify in Table 1. Whereas the minimum value of the fractal dimension was reported from sample SJ3 from the Lower Shajara reservoir as displayed in table1. The geometric relaxation time induced polarization fractal dimension and arithmetic relaxation time fractal dimension were observed to increase with increasing permeability as proofed intable1 owing to the possibility of having interconnected channels.

The Lower Shajara reservoir was denoted by four sandstone samples out of six, label as SJ1, SJ2, SJ3 and SJ4 as confirmed in figure1.Their geometric fractal dimension and arithmetic time fractal dimension values are proofed in table 1. As we proceed from sample SJ2 to SJ3 a pronounced reduction in permeability due to compaction was reported from $1955 \mathrm{md}$ to $56 \mathrm{md}$ which reflects decrease in geometric and arithmetic relaxation time fractal dimension from 2.7748 to 2.4379 as specified in table 1 . Again, an increase in grain size and permeability was recorded fractal dimension was found to be 2.6843 as described in table 1 .

In contrast, the Middle Shajara reservoir which is separated from the Lower Shajara reservoir by an unconformity surface as shown in figure 1. Itwas designated by three samples out of four, namely SJ7, SJ8, and SJ9 as illustrated in figure 1. Their geometric relaxation time induced polarization fractal dimensions (IPTg) and arithmetic relaxation time fractal dimensions (IPTa) show similarities as delineated in Table 1. Their fractal dimensions are higher than those of samples SJ3 and SJ4 from the Lower Shajara Reservoir due to an increase in their permeability as explained in table 1.

On the other hand, the Upper Shajara reservoiris separated from the Middle Shajara reservoir by yellow green mudstone as revealed in figure 1. It is defined by three samples so called SJ11, SJ12, SJ13 as explained in table 1. Moreover, their geometric relaxation time fractal dimension and arithmetic relaxation time fractal dimension are also higher than those of calculated from the measured capillary pressure date.The from sample SJ4 whose geometric fractal dimension and arithmetic

sample SJ3 and SJ4 from the Lower Shajara Reservoir due to an increase in their permeability as clarified in table 1.

Overall a plot of geometric relaxation time fractal dimension versus arithmetic relaxation time fractal dimension as shown in figure 2 reveals three permeable zones of varying Petrophysical properties. The higher fractal dimension zone with fractal dimension higher than 2.75 (Figure 2) corresponds to the complete Upper Shajara Reservoir, total Middle Shajara Reservoir and Sample SJ1 and SJ2 from the lower Shajara Reservoir. The middle fractal dimension zone with a value of about 2.68 (Figure 2) resembles sample SJ4 from the lower Shajara reservoir. The lower fractal dimension value2.43 allocates to sample SJ3 from the Lower Shajara reservoir as shown in (Figure 2).

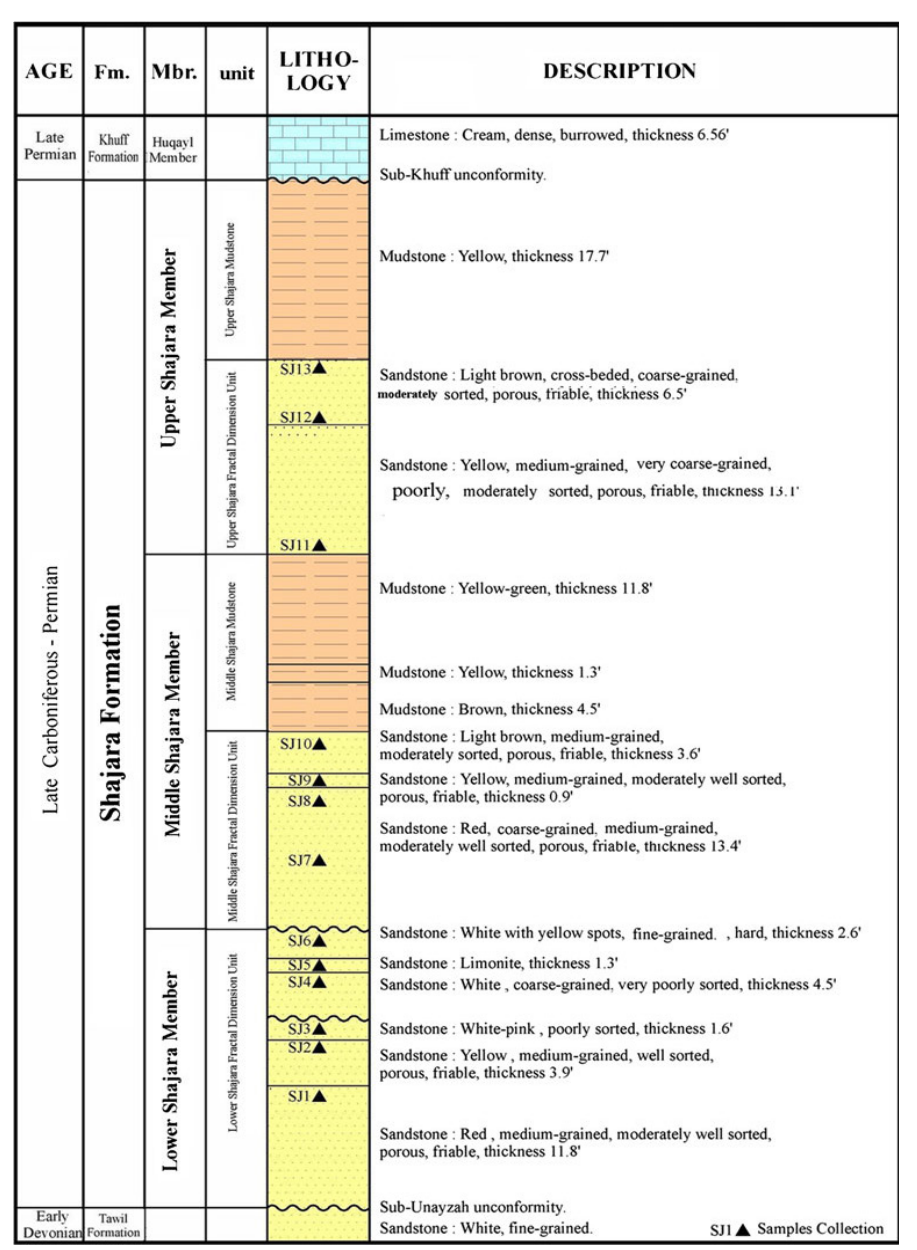

Figure 1. Surface type section of the Shajara reservoir of the Shajara formation of the Permo-Carboniferous Unayzah Group, Wadi Shajara, Qusayba area, al Qassim district, Saudi Arabia, N 2652 17.4, E 433618.

Table 1. Petrophysical model showing the three Shajara reservoir units with their Corresponding values of geometric and arithmetic relaxation time fractal Dimension of induced polarization.

\begin{tabular}{|l|l|l|l|l|l|}
\hline Reservoir & Sample & $\mathbf{\Phi} \%$ & $\mathbf{K}(\mathbf{m d})$ & $\begin{array}{l}\text { IPTg fractal } \\
\text { dimension }\end{array}$ & $\begin{array}{l}\text { IPTa fractal } \\
\text { dimension }\end{array}$ \\
\hline \multirow{2}{*}{$\begin{array}{l}\text { Upper Shajara } \\
\text { Reservoir }\end{array}$} & SJ13 & 25 & 973 & 2.7872 & 2.7872 \\
\cline { 2 - 6 } & SJ12 & 28 & 1440 & 2.7859 & 2.7859 \\
\cline { 2 - 6 } SJ11 & 36 & 1197 & 2.7586 & 2.7586 \\
\hline \multirow{2}{*}{$\begin{array}{l}\text { Middle Shajara } \\
\text { Reservoir }\end{array}$} & SJ9 & 31 & 1394 & 2.7786 & 2.7786 \\
\cline { 2 - 6 } & SJ8 & 32 & 1344 & 2.7752 & 2.7752 \\
\cline { 2 - 6 } SJ7 & 35 & 1472 & 2.7683 & 2.7683 \\
\hline \multirow{3}{*}{$\begin{array}{l}\text { Lower Shajara } \\
\text { Reservoir }\end{array}$} & SJ4 & 30 & 176 & 2.6843 & 2.6843 \\
\cline { 2 - 6 } & SJ3 & 34 & 56 & 2.4379 & 2.4379 \\
\cline { 2 - 6 } & SJ2 & 35 & 1955 & 2.7748 & 2.7748 \\
\cline { 2 - 6 } & SJ1 & 29 & 1680 & 2.7859 & 2.7859 \\
\hline
\end{tabular}




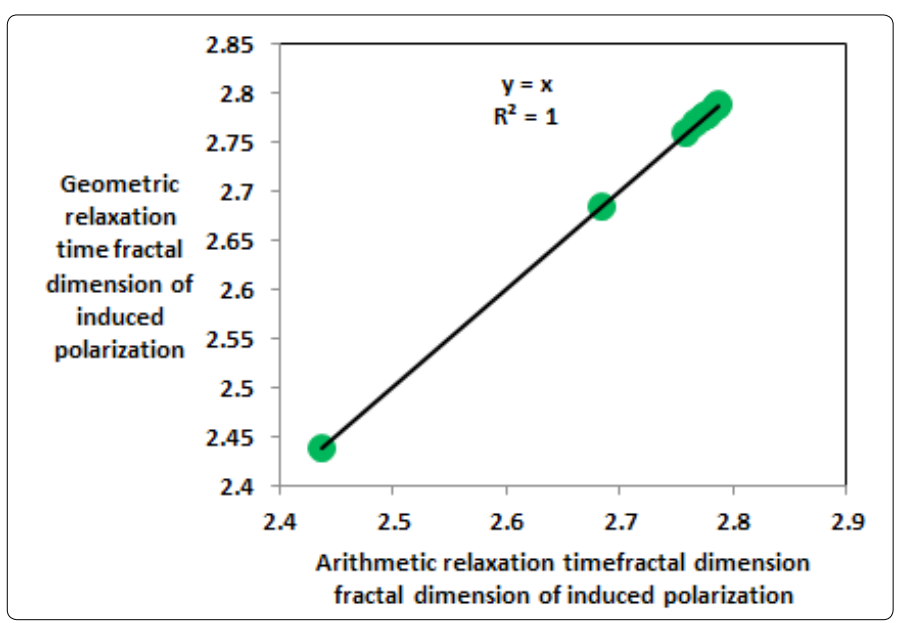

Figure 2. Arithmetic relaxation time fractal dimension versus geometric relaxation time fractal dimension of induced polarization showing three permeable zones.

\section{Conclusion}

* The sandstones of the Shajara Reservoirs of the Shajara formation of the permo-Carboniferous Unayzah group were divided here into three units based on geometric relaxation time fractal dimension of induced polarization.

* The Units from base to top are: Lower Shajara Geometric Relaxation time Fractal dimension Unit, Middle Shajara Relaxation Time Fractal Dimension Unit, and Upper Shajara Relaxation time Fractal Dimension Unit.

* These units were also proved by arithmetic relaxation time fractal dimension of induced polarization.

* The fractal dimension was found to increase with increasing grain size and permeability.

\section{References}

1. Schlumberger C. Etude sur la prospection electrique dusous-sol GauthierVillars, Paris 1920.

2. Schoeppel RJ, Thrasher JE. Laboratory study of induced polarization in sandstone rocks with varying salinity and shalyness. SPWLA 7th Annual Logging Symposium, 9-11 May, Tulsa, Oklahoma, 1966.

3. Maosong T, Weinan W, Li L, Yizhong J, Deqin S. Estimation of permeability of shaly sand reservoir frominduced polarization relaxation time spectra. J. Petrol. Sci. Eng. 2004; 45(1-2): 1-10. doi: 10.1016/j.petrol.2004.05.007

4. Liu X, Kong L, Zhang P, Zhou K. Permeability estimation using relaxationtime spectra derived from differential evolution inversion. J. Geophys. Eng. 2014; 11: 1-8. doi: 10.1088/1742-2132/11/1/015006

5. Al-Khidir KE, Al-Laboun A, Al-Qurishi A, Benzagouta MS. Bimodal Pore Size behavior of the Shajara formation reservoirs of the Permo-Carboniferous Unayzah group, Saudi Arabia. Journal of Petroleum Exploration and Production Technology. 2011; 1(1): 1-9. doi: 10.1007/s13202-011-0007-5

6. Al-Khidir KE, Benzagouta M, Al-Qurishi A, Al-Laboun A. Characterization of heterogeneity of the Shajara Reservoirs of the Shajara formation of the Permo-Carboniferous Unayzah group. Arabian Journal of Geosciences. 2013; 6 (10): 3989-3995. doi: 10.1007/s12517-012-0656-9

7. Al-Khidir, et al. Geoscience; New findings reported from King Saud University describe advances in geoscience. science letter. 2013; 359.

8. Al-Khidir KE, Benzagouta MS, Al-Quraishi AA, Al-Laboun AA. Differential capacity fractal dimension and water saturation fractal dimension as parameters for reservoir characterization: Shajara formation of the PermoCarboniferous Unayzah Group as a case study. 10th Meeting of the Saudi Society for Geoscience Geosciences for Sustainable Development 15-17 April 2013 KFUPM Campus, Dhahran, Saudi Arabia, 2013.

9. Al-Khidir KE. Pressure Head Fractal Dimension for Characterizing Shajara Reservoirs of the Shajara Formation of the Permo-Carboniferous Unayzah Group, Saudi Arabia. Arch Pet Environ Biotechnol. 2017; 2. 